Research Article

\title{
The Prevalence and Severity of Tooth Wear in Type 2 Diabetic Patients
}

\author{
Patcharawan Srisilapanan $\mathbb{D}^{1},{ }^{1}$ Matee Jindarat, ${ }^{2}$ and Jeffrey Roseman $^{3}$ \\ ${ }^{1}$ Center of Excellence in Dental Public Health, Faculty of Dentistry, Chiang Mai University, Chiang Mai, Thailand \\ ${ }^{2}$ Wiang $\mathrm{Pa}$ Pao Community Hospital, Wiang Pa Pao, Chiang Rai, Thailand \\ ${ }^{3}$ Professor Emeritus, Department of Epidemiology, UAB School of Public Health, University of Alabama, Tuscaloosa, \\ Alabama, USA \\ Correspondence should be addressed to Patcharawan Srisilapanan; patcharawana@gmail.com
}

Received 24 August 2018; Accepted 22 November 2018; Published 11 December 2018

Academic Editor: Gilberto Sammartino

Copyright (C) 2018 Patcharawan Srisilapanan et al. This is an open access article distributed under the Creative Commons Attribution License, which permits unrestricted use, distribution, and reproduction in any medium, provided the original work is properly cited.

\begin{abstract}
Objective. To assess the prevalence and severity of tooth wear in type 2 diabetic patients. Methods. Attendees at a diabetic clinic at Wiang Pa Pao Hospital in Chiang Rai province, Thailand, were invited to take part in this cross-sectional study. All participants were aged 35-74 and had type 2 diabetes. Participants were required to have been diagnosed with diabetes for at least three months. 179 subjects accepted a clinical oral examination and completed the questionnaire. Tooth wear was assessed clinically using the Smith and Knight Tooth Wear Index. Results. The mean age of diabetic patients was $56.5 \pm 7.8$ years. The majority $(44.1 \%)$ had diabetes more than 5 years. The average years of having had diabetes was $6.5 \pm 6.3$ years. The most prevalent type of tooth wear was attrition (99.4\%). The prevalence of erosion, abrasion, and abfraction were $64.8 \%, 31.3 \%$, and $7.3 \%$, respectively. The majority of the tooth wear was moderate to high severity (62.1\%). Erosion and abfraction showed significant association with age group $(p<0.05)$. Age group was significantly associated with the severity level $(p=0.017)$. Mild tooth wear severity was the highest in age groups 35-44 and 45-54 (53.8\% and 41.2\%, respectively). Moderate tooth wear was the highest proportion in age groups 55-65 and 65-74 (52.2\% and 44.0\%, respectively). There were no significant differences between specific diabetic symptoms and types of tooth wear. Conclusion. There was a high prevalence of tooth wear among diabetic patients. The role of prevention is vital in maintaining the integrity of the teeth and to avoid treating these worn teeth in diabetic patients.
\end{abstract}

\section{Background}

Older people are living longer and maintaining more natural teeth. Functional teeth are important for eating and enable older people to consume normal and healthy food. However, natural tooth retention is negatively affected by tooth wear. Tooth wear has recently been accepted as a major oral health problem [1-3]. Tooth wear is a progressive condition that affects dentition throughout life. Tooth wear affects both function and esthetics. The most important function affected is eating as worn teeth cannot be effectively used to bite and chew food [4]. Therefore, older patients suffer and seek dental treatment related to tooth wear.

Tooth wear includes attrition, abrasion, erosion, and abfraction. Attrition is the loss of tooth occlusal surfaces due to the force of tooth against tooth. Abrasion is the wear on buccal surfaces related to forces mainly caused from tooth brushing. Erosion is the loss of dental hard tissue from combined chemical-mechanical forces related to acids from diet [5]. Treatment of excessive tooth wear is complicated, expensive, and time-consuming. A study on the cost of prosthodontic rehabilitation of erosive tooth wear for $\mathrm{Na}$ tional Health Service hospitals in the United Kingdom confirmed that rehabilitation is complex, interdisciplinary, and costly [3]. People in rural areas who are poor may not be able to afford sophisticated treatments such as crowns and bridges.

There are several extrinsic factors related to different types of tooth wear [5-9]. Extrinsic factors for dental erosion are commonly found to be related to diet and dietary 
behaviors [5]. Acid in one's diet is the main cause of erosion. Common dietary acids associated with acid erosion are found in citrus fruits or fruit juices, carbonated drinks, wine, and vinegar [5-7]. Factors related to tooth attrition included bruxism, chewing patterns, etc [8]. Abrasion is usually associated with tooth brushing forces and pattern and abrasive particles in toothpastes [9].

Tooth wear can be found in all age groups. However, it is more prevalent and more severe in adults and older people [10-13]. Yadav [11] studied 500 subjects aged 18 to 55 in India. He found a high prevalence of tooth wear $(88 \%)$ in older people. A study of 704 adults in China found more than $80 \%$ of tooth wear in premolar and molar teeth [12]. In Dutch adult population, the prevalence of moderate tooth wear was $80 \%$ [13]. In Thailand, there are very few studies on tooth wear. There have been studies on tooth wear in teenagers [14] but no studies on tooth wear in older adult groups.

Diabetes is one of the most common noncommunicable diseases found in older people [15]. Over $60 \%$ of people with diabetes worldwide live in Asia, with prevalence across countries ranging from $3 \%$ to $47.3 \%$. There is a high prevalence of diabetes in Thailand [15]. Data from the National Health Examination Survey (NHES) of Thailand in 2004, 2009, and 2014 reported an increase over time in the age-adjusted prevalence of diabetes in individuals aged 20 and above. The increase ranged from $7.7 \%$ in 2004 to $7.8 \%$ in 2009 and $9.9 \%$ in 2014 . The prevalence of diabetes in those who were 60 years old and above in 2014 was $15.3 \%$ in males and $20.3 \%$ in females [16]. It is therefore considered as a major public health problem. Diabetic patients are one important target groups for oral health care under the policy of the Thailand Ministry of Public Health. Diabetic patients are among the largest group for dentists to apply oral health prevention and promotion to achieve good oral and overall health. The primary care services at all community hospitals in Thailand give high emphasis on patients with diabetes. Dental practitioners should be aware of the prevalence and severity as well as the underlying factors related to tooth wear. It is therefore worthwhile to investigate the prevalence and severity of tooth wear among diabetic patients in northern Thailand.

\section{Materials and Methods}

This cross-sectional, descriptive, and analytic survey was conducted in Wiang Pa Pao District, Chiang Rai province, Northern Thailand. The total number of diabetic patients at Wiang Pa Pao hospital in 2012 was 1,911. Using quota sampling according to age groups, the calculation of the sample size was 150.179 subjects participated in this study. Diabetic patients were identified by the medical doctor as those who had fasting blood sugar (FBS) $\geq 140$ at least once among three consecutive blood sample screenings during their three-month period of hospital visits. These patients attended the diabetic clinic at the Wiang Pa Pao Community Hospital and Health Promoting Hospitals in Wiang Pa Pao District.

\section{Data Collection}

In this study, the term tooth wear includes attrition, erosion, abrasion, and abfraction. This study used the classification of tooth wear and the severity score according to Smith and Knight Tooth Wear index [17]. Smith and Knight Tooth Wear Index (TWI) is a worldwide acceptable and widely used index to assess tooth wear $[13,18,19]$. TWI is good for diagnostic purposes. It could assess the amount of the surface area involved and the depth of the surface loss [19]. One other advantage of this index is that it could determine the severity of wear on each surface. Each tooth was recorded for wear on all four surfaces (buccal, cervical, lingual, and incisal-occlusal), irrespective of the etiology of tooth wear. Only one diagnostic was given for each tooth.

One dentist (MJ) examined all subjects. The examiner was trained the use of Smith and Knight Index with the expert who was a professor in a dental school prior to the examination. Intraexaminer reliability was performed during the examination. Every 10 subjects examined, one subject would be re-examined which covered 10 percent of the total subjects. 18 subjects were included in the intraexaminer reliability from the total 179 subjects. Cohen's kappa coefficient was 0.88 which represented high reliability. Patients were examined in the dental clinic at Wiang Pa Pao Community Hospital. Data were collected during a threemonth period from June to August 2013. Descriptive statistics, a chi-squared test, and a Fisher Exact test were used for data analysis.

\section{Questionnaire}

A face to face interview was performed by two dental nurses. The nurses were trained by a qualified dentist. The questionnaire was developed by the authors (PS and MJ) to include demographic information and related health factors. Content validity of the questionnaire was performed by three dental public health experts. The questionnaire was pretested in 30 subjects who had similar characteristics with the study subjects.

\section{Results}

The majority (69.9\%) of the subjects were female. The mean age was $56.5( \pm 7.8)$. Almost half $(44.1 \%)$ of diabetic cases had diabetes more than five years. The vast majority $(90.5 \%)$ were uncontrolled. Approximately $70 \%$ had no complications. The most common complication was diabetic nephropathy (Table 1). Attrition was the most prevalent sign of tooth wear (99.4\%), with almost all subjects showing some sign, followed in order by erosion (64.8\%), abrasion (31.3\%), and abfraction $(7.3 \%)$. Erosion and abfraction showed significant association with age group $(p<0.05)$ (Table 2$)$. The majority of the tooth wear was of moderate to high severity. Age group was significantly associated with severity level $(p=0.017)$. Mild tooth wear severity was the highest proportion found in age groups 35-44 years and 45-54 years (53.8\% and $41.2 \%$, respectively). Moderate tooth wear was the highest proportion found in age groups 55-65 years and 
TABle 1: Characteristics of the study population $(n=179)$.

\begin{tabular}{|c|c|}
\hline Characteristics & $n(\%)$ \\
\hline \multicolumn{2}{|l|}{ Sex } \\
\hline Male & $61(34.1)$ \\
\hline Female & $118(65.9)$ \\
\hline \multicolumn{2}{|l|}{ Age (years) } \\
\hline $35-44$ & $13(7.3)$ \\
\hline $45-54$ & $51(28.5)$ \\
\hline $55-64$ & $90(50.3)$ \\
\hline $65-74$ & $25(14.0)$ \\
\hline Mean \pm SD & $56.5 \pm 7.8$ \\
\hline \multicolumn{2}{|l|}{ Duration of having diabetes } \\
\hline Less than $1 \mathrm{yr}$ & $30(16.8)$ \\
\hline $1-5 \mathrm{yrs}$ & $70(39.1)$ \\
\hline More than 5 yrs & $79(44.1)$ \\
\hline Mean \pm SD & $6.5 \pm 6.3$ \\
\hline \multicolumn{2}{|l|}{ Fast blood sugar (FBS) } \\
\hline Controlled & $17(9.5)$ \\
\hline Uncontrolled & $162(90.5)$ \\
\hline \multicolumn{2}{|l|}{ Complication from diabetes } \\
\hline No complication & $127(70.9)$ \\
\hline At least one complication & $52(29.1)$ \\
\hline \multicolumn{2}{|l|}{ Type of complication $(n=52)$} \\
\hline Diabetic retinopathy & $7(13.5)$ \\
\hline Diabetic nephropathy & $42(80.8)$ \\
\hline Peripheral vascular disease & $6(11.5)$ \\
\hline Coronary vascular disease (remarks: four patients had two complications) & $1(2.0)$ \\
\hline
\end{tabular}

TABle 2: Prevalence of tooth wear according to age group.

\begin{tabular}{|c|c|c|c|c|c|}
\hline Age group (years) & $n$ & $\begin{array}{c}\text { Attrition } \\
n(\%)\end{array}$ & $\begin{array}{c}\text { Erosion } \\
n(\%)\end{array}$ & $\begin{array}{c}\text { Abrasion } \\
n(\%)\end{array}$ & $\begin{array}{c}\text { Abfraction } \\
n(\%)\end{array}$ \\
\hline $35-44$ & 13 & $12(92.3)$ & $5(38.5)$ & $2(15.4)$ & $3(23.1)$ \\
\hline $45-54$ & 51 & $51(100.0)$ & $29(56.9)$ & $21(41.2)$ & $1(2.0)$ \\
\hline $55-64$ & 90 & $90(100.0)$ & $66(73.3)$ & $25(27.8)$ & $9(10.0)$ \\
\hline $65-74$ & 25 & $25(100.0)$ & $16(64.0)$ & $8(32.0)$ & $0(0.0)$ \\
\hline$p$ value $^{\mathrm{a}}$ & & 0.073 & 0.041 & 0.242 & 0.021 \\
\hline
\end{tabular}

${ }^{\mathrm{a}}$ Fisher exact test.

65-74 years (52.2\% and $44.0 \%$, respectively) as shown in Table 3. There were no significant differences in the frequencies of any of the signs of tooth wear with respect to characteristic of diabetes (Table 4).

\section{Discussion}

Our results confirm that tooth wear is highly prevalent in Thai adults and older adults. Moreover, tooth wear is very common among those with diabetes in Thailand. Studies on tooth wear in diabetic patients are rare in Thailand. As with other studies of adults, this study showed a high prevalence of tooth wear [10-13]. Similar findings were reported in a study of tooth wear in the aging population of northwest China, where the prevalence of tooth wear ranged from $85.5 \%$ in molar to $100 \%$ in canine teeth [12]. The prevalence of attrition in our study is higher than the study in the Indian subjects [11]. However, all previous studies included subjects with different age ranges than ours. This might affect the prevalence of tooth wear. When investigating the tooth wear severity, the moderate tooth wear (level 3) in our study in those 60 years and above was lower than the Dutch population who were $65-74$ years $(24.0 \%$ vs $82.0 \%)$ [13]. Several studies also found that the severity of tooth wear increased when age increased $[13,20,21]$.

The data from our study as well as previous studies gave an implication that the prevalence of tooth wear is high and becoming an important dental public health problem. It could be due to the accumulation of certain dietary patterns, high consumption of citrus fruits, inappropriate brushing technique, and parafunctional habits $[22,23]$.

\section{Limitations of the Study}

Our study has some limitations. There are some limitations of the TWI index. It is a multifactorial tooth wear index; 
TABLE 3: Severity of different types of tooth wear according to age group $(n=179)$.

\begin{tabular}{|c|c|c|c|c|c|c|}
\hline \multirow{2}{*}{ Severity level } & \multirow{2}{*}{$n$} & \multicolumn{4}{|c|}{ Age group } & \multirow{2}{*}{$p$ value } \\
\hline & & $35-44$ yrs. $n(\%)$ & $45-54$ yrs. $n(\%)$ & $55-64$ yrs. $n(\%)$ & $65-74$ yrs. $n(\%)$ & \\
\hline No tooth wear (level 0 ) & 1 & $1(7.7)$ & $0(0.0)$ & $0(0.0)$ & $0(0.0)$ & 0.073 \\
\hline Very mild (level 1) & 9 & $2(15.4)$ & $1(2.0)$ & $5(5.6)$ & $1(4.0)$ & 0.242 \\
\hline Mild (level 2) & 58 & $7(53.8)$ & $21(41.2)$ & $23(25.6)$ & $7(28.0)$ & 0.083 \\
\hline Moderate (level 3) & 76 & $2(15.4)$ & $16(31.4)$ & $47(52.2)$ & $11(44.0)$ & 0.018 \\
\hline Severe (level 4) & 35 & $1(7.7)$ & $13(25.5)$ & $15(16.7)$ & $6(24.0)$ & 0.407 \\
\hline Total & 179 & $13(100.0)$ & $51(100.0)$ & $90(100.0)$ & $25(100.0)$ & 0.017 \\
\hline
\end{tabular}

${ }^{\mathrm{a}}$ Fisher's exact test.

TABLE 4: Tooth wear and diabetic status.

\begin{tabular}{|c|c|c|c|c|c|}
\hline Diabetic status & & $\begin{array}{c}\text { Attrition } \\
n(\%)\end{array}$ & $\begin{array}{c}\text { Erosion } \\
n(\%)\end{array}$ & $\begin{array}{c}\text { Abrasion } \\
n(\%)\end{array}$ & $\begin{array}{c}\text { Abfraction } \\
n(\%)\end{array}$ \\
\hline \multicolumn{6}{|l|}{ Duration of having diabetes } \\
\hline Less than $1 \mathrm{yr}$ & 30 & $29(96.7)$ & $19(63.3)$ & $12(40.0)$ & $2(6.7)$ \\
\hline $1-5 \mathrm{yrs}$ & 70 & $70(100.0)$ & $47(67.1)$ & $19(27.1)$ & $4(5.7)$ \\
\hline More than 5 yrs & 79 & $79(100.0)$ & $50(63.3)$ & $25(31.6)$ & $7(8.9)$ \\
\hline$p$ value $^{\mathrm{a}}$ & & 0.168 & 0.893 & 0.441 & 0.862 \\
\hline \multicolumn{6}{|l|}{ Fast blood sugar (FBS) } \\
\hline Controlled & 17 & $17(100.0)$ & $12(70.6)$ & $8(47.5)$ & $3(17.6)$ \\
\hline Uncontrolled & 162 & $161(99.4)$ & $104(64.2)$ & $48(29.6)$ & $10(6.2)$ \\
\hline$p$ value $^{\mathrm{a}}$ & & 1.00 & 0.791 & 0.171 & 0.112 \\
\hline \multicolumn{6}{|l|}{ Complication from diabetes } \\
\hline No complication & 127 & $126(99.2)$ & $81(63.8)$ & $41(32.3)$ & $10(7.9)$ \\
\hline At least one complication & 52 & $52(100.0)$ & $35(67.3)$ & $15(28.8)$ & $3(5.8)$ \\
\hline$p$ value $^{\mathrm{a}}$ & & 1.00 & 0.732 & 0.724 & 0.759 \\
\hline
\end{tabular}

${ }^{a}$ Fisher's exact test.

therefore, only one single code for each surface irrespective of cause. Therefore, in some tooth surfaces, there might be tooth wear due to erosion and attrition. The data could be missing. Since we did not assess the frequencies and severity of tooth wear in a sample without diabetes, we cannot say whether those with diabetes have greater tooth wear than those without diabetes. Therefore, the findings should be interpreted with caution. However, our results do suggest that tooth wear is present in those with diabetes regardless of diabetes characteristics. This suggests that it is important for the dental practitioner to evaluate periodontal disease as well as tooth wear and assist patients in developing a satisfactory diabetic diet. A diet high in raw fruits and vegetables, nuts, and unrefined grains may be difficult for those with severe tooth wear.

\section{Conclusion}

There was a high prevalence of tooth wear among diabetic patients. The role of prevention is vital in maintaining the integrity of the teeth and to avoid treating those worn teeth in diabetic patients.

\section{Data Availability}

The data used to support the findings of this study are available from the corresponding author upon request.

\section{Ethical Approval}

This study was approved by the Ethical Committee of the Graduate School, Chiang Mai University.

\section{Consent}

Diabetic patients who met the inclusion criteria were asked to voluntarily participate in this study. They signed the consent form prior to the oral examination and the interview.

\section{Disclosure}

The partial content of this manuscript had been presented as conference abstract in IADR General Session \& Exhibition, Cape Town, South Africa, 25-28 June 2014.

\section{Conflicts of Interest}

The authors declare that there are no conflicts of interest regarding the publication of this paper.

\section{Authors' Contributions}

PS and MJ carried out the design, analysis, and writing of the paper. MJ collected the data. JR assisted in the writing and editing. All the authors have read and approved the final paper. 


\section{Acknowledgments}

We would like to thank the health and dental health team at Wiang Pa Pao Hospital for their kind assistance. We are grateful for the partial funding of this research from Chiang Mai University.

\section{References}

[1] A. Lee, L. H. He, K. Lyons, and M. V. Swain, "Tooth wear and wear investigations in dentistry," Journal of Oral Rehabilitation, vol. 39, no. 3, pp. 217-225, 2012.

[2] R. Omar, A. Johansson, A. K. Johansson, and G. E. Carlsson, "Tooth wear," International Journal of Dentistry, vol. 2012, Article ID 731085, 1 pages, 2012.

[3] S. O'Toole, M. Pennington, S. Varma, and D. W. Bartlett, "The treatment need and associated cost of erosive tooth wear rehabilitation - a service evaluation within an NHS dental hospital," BDJ, vol. 224, no. 12, pp. 957-961, 2018.

[4] S. B. Mehta, S. Banerji, B. J. Millar, and J. M. Suarez-Feito, "Current concepts on the management of tooth wear: part 1. Assessment, treatment planning and strategies for the prevention and the passive management of tooth wear," British Dental Journal, vol. 212, no. 1, pp. 17-27, 2012.

[5] D. W. Bartlett, J. Fares, S. Shirodaria, K. Chiu, N. Ahmad, and M. Sherriff, "The association of tooth wear, diet and dietary habits in adults aged 18-30 years old," Journal of Dentistry, vol. 39, no. 12, pp. 811-816, 2011.

[6] J. M. Gate and T. Imfeld, "Dental erosion, summary," European Journal of Oral Sciences, vol. 104, no. 2, pp. 241-244, 1996.

[7] P. Kanzow, F. J. Wegehaupt, T. Attin, and A. Wiegand, "Etiology and pathogenesis of dental erosion," Quintessence International, vol. 47, no. 4, pp. 275-278, 2016.

[8] J. S. Rees and S. Somi, "A guide to the clinical management of attrition,” BDJ, vol. 224, no. 5, pp. 319-323, 2018.

[9] I. Kontaxopoulou and S. Alam, "Risk assessment for tooth wear," Primary Dental Journal, vol. 4, no. 3, pp. 25-29, 2015.

[10] B. Smith and N. Robb, "The prevalence of tooth wear in 1007 dental patients," Journal of Oral Rehabilitation, vol. 23, no. 4, pp. 232-239, 1996.

[11] S. Yadav, "A study on prevalence of dental attrition and its relation to factors of age, gender and to the signs of TMJ dysfunction," Journal of Indian Prosthodontic Society, vol. 11, no. 2, pp. 98-105, 2011.

[12] B. Liu, M. Zhang, Y. Chen, and Y. Yao, "Tooth wear in aging people: an investigation of the prevalence and the influential factors of incisal/occlusal tooth wear in northwest China," BMC Oral Health, vol. 14, no. 1, p. 65, 2014.

[13] P. Wetselaar, J. H. Vermaire, C. M. Visscher, F. Lobbezoo, and A. A. Schuller, "The prevalence of tooth wear in the Dutch adult population," Caries Research, vol. 50, no. 6, pp. 543-550, 2016.

[14] W. Aekplakorn, S. Chariyalertsak, P. Kessomboon, S. Assanangkornchai, S. Taneepanichskul, and P. Putwatana, "Prevalence of diabetes and relationship with socioeconomic status in the Thai population: national health examination survey, 2004-2014," Journal of Diabetes Research, vol. 2018, Article ID 1654530, 8 pages, 2018.

[15] K. Denys, M. Cankurtaran, W. Janssens, and M. Petrovic, "Metabolic syndrome in the elderly: an overview of the evidence," Acta Clinica Belgica, vol. 64, no. 1, pp. 23-34, 2009.
[16] A. Nanditha, R. C. Ma, A. Ramachandran et al., "Diabetes in Asia and the Pacific: implications for the global epidemic," Diabetes Care, vol. 39, no. 3, pp. 472-485, 2016.

[17] B. G. Smith and J. K. Knight, "An index for measuring the wear of teeth," British Dental Journal, vol. 156, no. 12, pp. 435-438, 1984.

[18] P. Wetselaar, A. Faris, and F. Lobbezoo, "A plea for the development of an universally accepted modular tooth wear evaluation system," BMC Oral Health, vol. 16, no. 1, p. 115, 2016.

[19] B. Sterenborg, S. I. Kalaykova, B. Loomans, and M. Huysmans, "Impact of tooth wear on masticatory performance," Journal of Dentistry, vol. 76, pp. 98-101, 2018.

[20] O. Bernhardt, D. Gesch, C. Splieth et al., "Risk factors for high occlusal wear scores in a population-based sample: results of the study of health in Pomerania (SHIP)," International Journal of Prosthodontics, vol. 17, no. 3, pp. 333-339, 2004.

[21] A. Van't Spijker, J. M. Rodriguez, C. M. Kreulen, E. M. Bronkhorst, D. W. Bartlett, and N. H. Creugers, "Prevalence of tooth wear in adults," International Journal of Prosthodontics, vol. 22, no. 1, pp. 35-42, 2009.

[22] FM. Burke and G. McKenna, "Tooth wear and the older patient," Dental Update, vol. 38, no. 3, pp. 165-168, 2011.

[23] S. O'Toole and F. Mullan, "The role of the diet in tooth wear," BDJ, vol. 224, no. 5, pp. 379-383, 2018. 


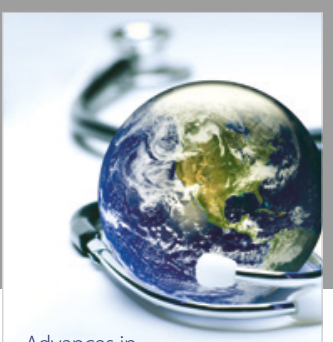

Advances in
Public Health

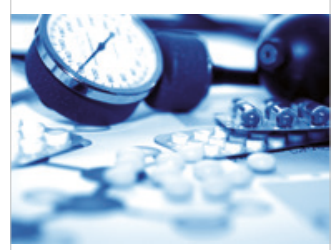

Case Reports in

Medicine

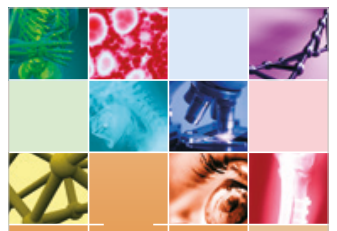

niernational Journal of

Biomaterials
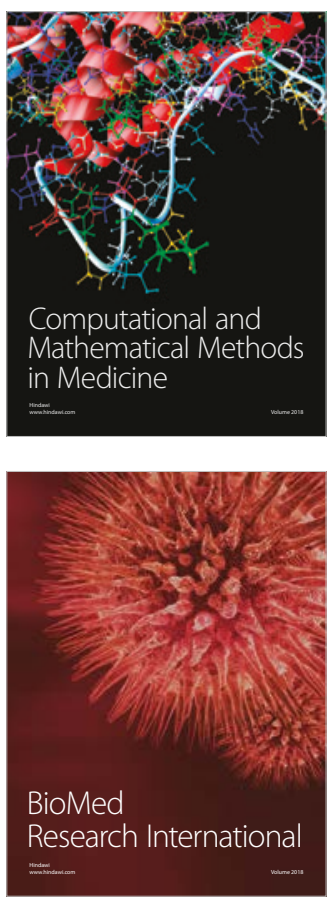

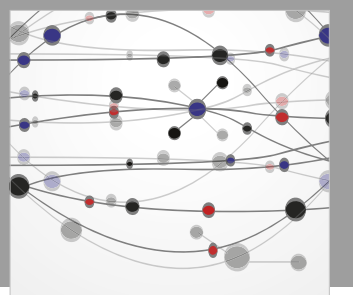

The Scientific World Journal Dentistry

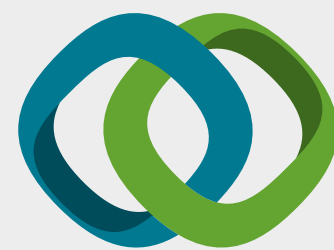

Hindawi

Submit your manuscripts at

www.hindawi.com
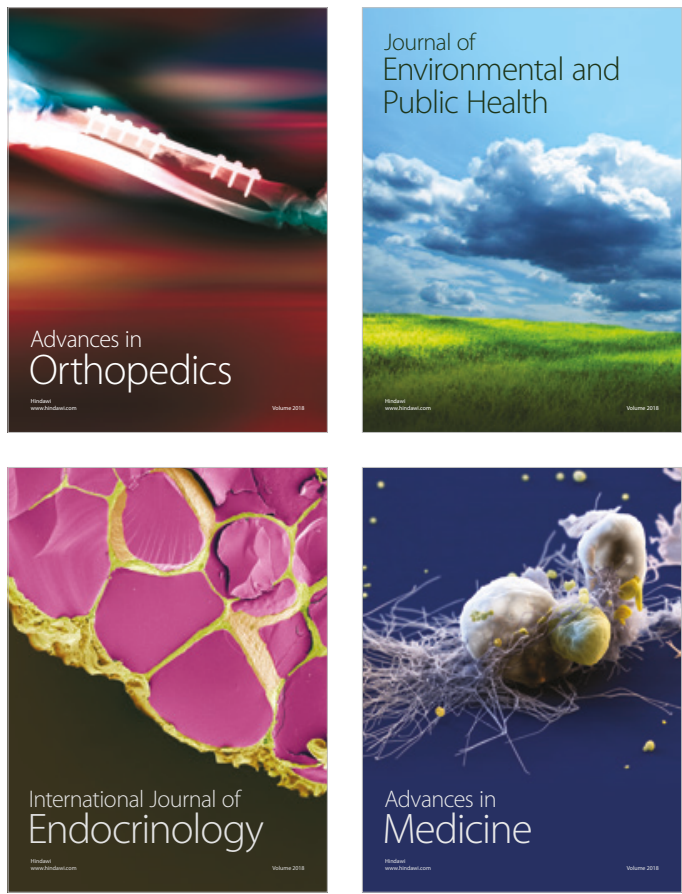
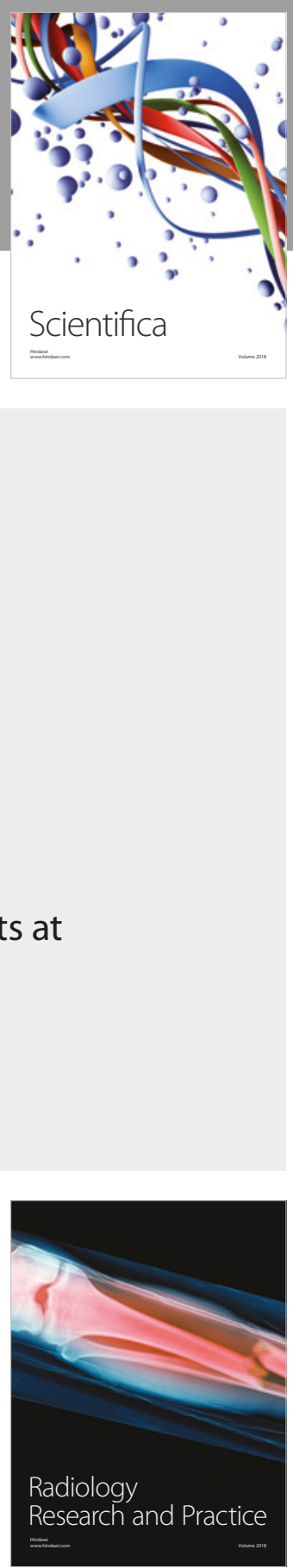

Scientifica

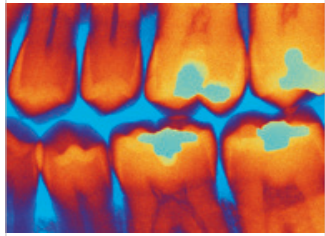

Case Reports in

Dentistry
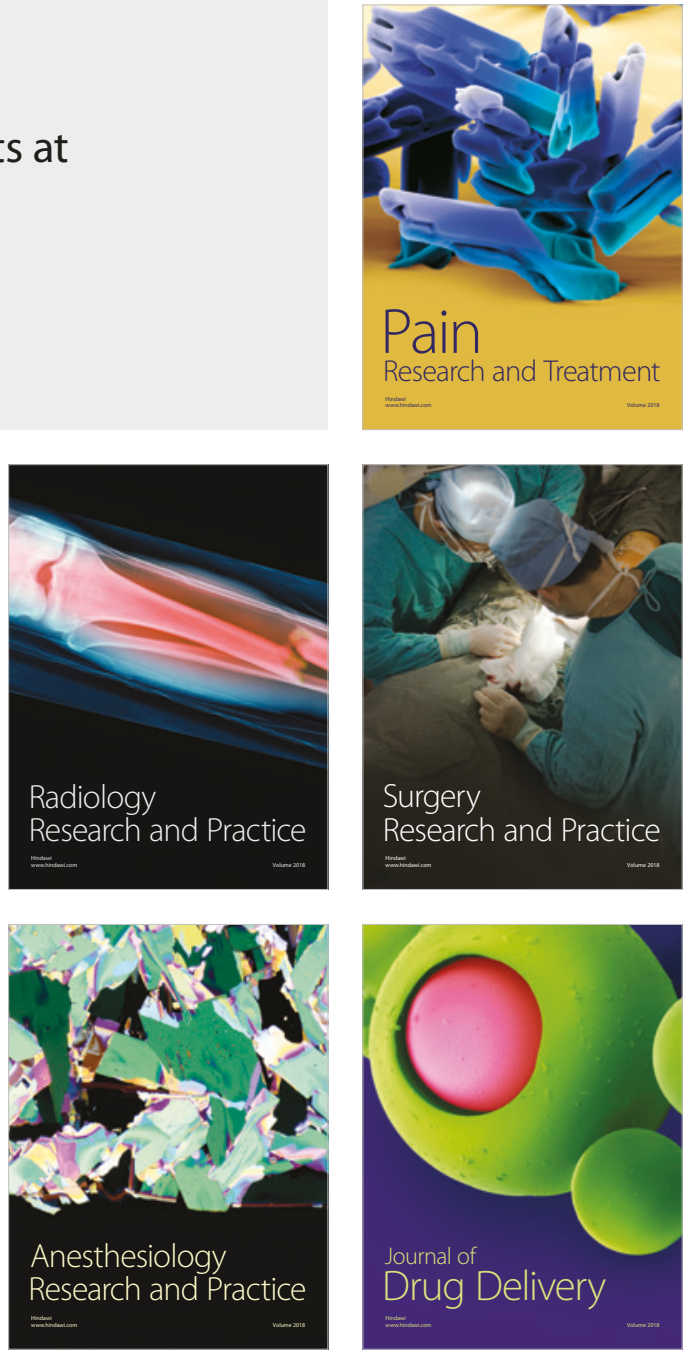